\title{
Risk factors and comorbidities associated with magnesium deficiency in pregnant women and women with hormone-related conditions: analysis of a large real-world dataset
}

Svetlana Orlova ${ }^{1}$, Galina Dikke ${ }^{2}$, Gisele Pickering ${ }^{3}$, Natalya Yaltseva ${ }^{4}$, Sofya Konchits ${ }^{5}$, Kirill Starostin ${ }^{5^{*}}$ (D) and Alina Bevz ${ }^{5}$

\begin{abstract}
Background: An accumulating body of literature indicates that magnesium deficiency is associated with a number of hormone-related conditions (HRC) in women, and epidemiological studies are needed to assess its prevalence and risk factors. Here, we present a secondary analysis of data pooled from four large observational studies that assessed magnesium deficiency among pregnant women and women with HRC across the Russian Federation.

Methods: The main objective of this analysis was to estimate the prevalence of magnesium deficiency in this population and to describe risk factors and comorbidities associated with low serum magnesium. Univariate logistic regression analysis was performed to identify the risk factors and comorbid conditions associated with an increased risk of low serum magnesium level.
\end{abstract}

Results: A total of 983 pregnant women and 9444 women with HRC were eligible for analysis. Prevalence of hypomagnesemia (magnesium serum level cut-off $<0.66 \mathrm{mmol} / \mathrm{L} /<0.8 \mathrm{mmol} / \mathrm{L}$ ) was $34.0 \% / 78.9 \%$ in pregnant women and $21.4 \% / 54.8 \%$ in women with HRC. The highest prevalence of magnesium deficiency was observed for osteoporosis and climacteric syndrome. Risk factors included diastolic blood pressure, previous pregnancy complications, infections and edema for pregnant women, and age, body mass index, and various comorbidities for women with HRC.

Conclusions: These results confirm the high prevalence of hypomagnesemia in pregnant women and women with HRC and underline the importance of routine screening, since risk factors are mostly non-specific.

Keywords: Magnesium deficiency, Osteoporosis, Climacteric syndrome, Pregnancy, Hormone replacement therapy, Oral contraceptives

\footnotetext{
* Correspondence: Kirill.Starostin@sanofi.com

${ }^{5}$ Department of Medical Affairs, Sanofi, Moscow, Russia

Full list of author information is available at the end of the article
}

(c) The Author(s). 2021 Open Access This article is licensed under a Creative Commons Attribution 4.0 International License, which permits use, sharing, adaptation, distribution and reproduction in any medium or format, as long as you give appropriate credit to the original author(s) and the source, provide a link to the Creative Commons licence, and indicate if changes were made. The images or other third party material in this article are included in the article's Creative Commons licence, unless indicated otherwise in a credit line to the material. If material is not included in the article's Creative Commons licence and your intended use is not permitted by statutory regulation or exceeds the permitted use, you will need to obtain permission directly from the copyright holder. To view a copy of this licence, visit http://creativecommons.org/licenses/by/4.0/ The Creative Commons Public Domain Dedication waiver (http://creativecommons.org/publicdomain/zero/1.0/) applies to the data made available in this article, unless otherwise stated in a credit line to the data. 


\section{Background}

Magnesium is one of the essential minerals and is involved in a plethora of metabolic functions. Magnesium deficiency is associated with a range of diseases and conditions, such as hypertension, diabetes, neurological and cardiovascular event [1]. It is estimated that $48-60 \%$ of adults do not achieve the average recommended dietary intake of magnesium, and 15-42\% of apparently healthy individuals have been shown to have magnesium deficiency [2-4]. Magnesium deficiency is more frequent in women than men [2, 4]; this may partially be influenced by the fact that estrogen stimulates magnesium utilization by tissues and therefore hormonal rhythms in women may affect and modulate magnesium status [5].

Assessing magnesium levels may present a challenge because of its predominant retention in soft tissues and bones. Magnesium in the blood only accounts for about $0.8 \%$ of all magnesium in the body, with $0.3 \%$ contained in serum and $0.5 \%$ in red blood cells [4]. Since magnesium level is most frequently assessed by measuring blood serum concentration, magnesium deficiency may be masked by apparently normal serum levels and its prevalence may be underestimated [1, 3 , 6]. Furthermore, there is no uniform lower reference limit for serum magnesium level, with cut-offs ranging between $0.66 \mathrm{mmol} / \mathrm{L}$ and $0.85 \mathrm{mmol} / \mathrm{L}$ in different studies [2, 7, 8].

Although the majority of adults will not experience serious consequences, subclinical magnesium deficiency may have a more profound effect on individuals in high risk groups, e.g. pregnant women and women undergoing menopause, who are at risk of osteoporosis [2]. Pregnancy is associated with an increased magnesium requirement resulting from a combination of fetal demand, altered tissue distribution and an increased renal output of magnesium [9]. It is recommended to closely monitor magnesium levels in pregnant women with kidney disease [10]. Recent studies suggest that low magnesium during pregnancy may be associated with adverse maternal and fetal outcomes including preeclampsia and fetal growth retardation, although there is no consensus on the benefit of magnesium supplementation in preventing these outcomes $[9,11-15]$. An accumulating body of literature indicates that magnesium deficiency may also be linked to various other aspects of women's health, such as menopause, osteoporosis and use of oral contraceptives [16, 17].

Although the importance of magnesium in pregnancy and various hormone-related conditions is widely recognized, further studies are needed to establish the prevalence of magnesium deficiency and to what extent low magnesium levels can be linked to patient outcomes and comorbidities. To this end, four large observational studies were conducted between 2012 and 2016 across the
Russian Federation. The studies assessed the prevalence and clinical management of magnesium deficiency in pregnant women (MAGIC, MAGIC2) and in women with hormone-related conditions (MAGYN, MAGYN2) using a magnesium deficiency questionnaire (MDQ) and a blood test assessing serum magnesium levels [18-21].

These studies showed an unexpectedly high prevalence of magnesium deficiency, assessed using both MDQ and blood magnesium test [18-21]. Here, we present the results of a secondary analysis of the prevalence of magnesium deficiency in women with hormone-related conditions and pregnant women with symptoms of magnesium deficiency in the pooled population and evaluate its association with risk factors and comorbidities related to magnesium deficiency in these cohorts.

\section{Methods}

\section{Study design and patients}

This manuscript summarizes a part of the secondary analysis of pooled data collected in four observational studies of magnesium deficiency in pregnant women and women with hormone-related conditions: MAGIC (DIREGL06157), MAGIC2 (DIREGL06468), MAGYN (MAGNEL06863), and MAGYN2 (MAGNEL07741) [18-21].

MAGIC and MAGIC2 enrolled pregnant women $(N=$ 1130 and $N=2117$, respectively) during routine visits to maternity welfare centers. Women were included in the studies if they were $>18$ years of age, were pregnant and had suspected magnesium deficiency (fatigue, muscle cramps, etc.). The study excluded women who reported other known or obvious reasons for magnesium deficiency beside pregnancy $[19,21]$. MAGYN and MAGY N2 studies enrolled women with hormone-related conditions ( $N=9168$ and $N=11,424$, respectively) attending outpatient clinics. Women were included if they were 18-60 years of age and used hormonal contraception or hormone replacement therapy (HRT) or had one of the following conditions: premenstrual syndrome (PMS), climacteric syndrome without HRT, osteoporosis or other hormonal conditions (including endometriosis, polycystic ovarian disease, uterine leiomyoma, dysmenorrhea, endometrial hyperplasia). Women were excluded if they had severe conditions potentially hindering participation in the study or were receiving magnesium supplementation at baseline $[18,20]$.

The present analysis included all patients who fulfilled the inclusion/exclusion criteria in the studies (Fig. 1). Patients with missing data, contradictory/inconsistent data or outlier data were excluded from the analysis (exclusion was performed separately for each variable of interest). Patient characteristics, available medical history and serum magnesium test results were combined in two pooled databases ('pregnant women' and 'women 


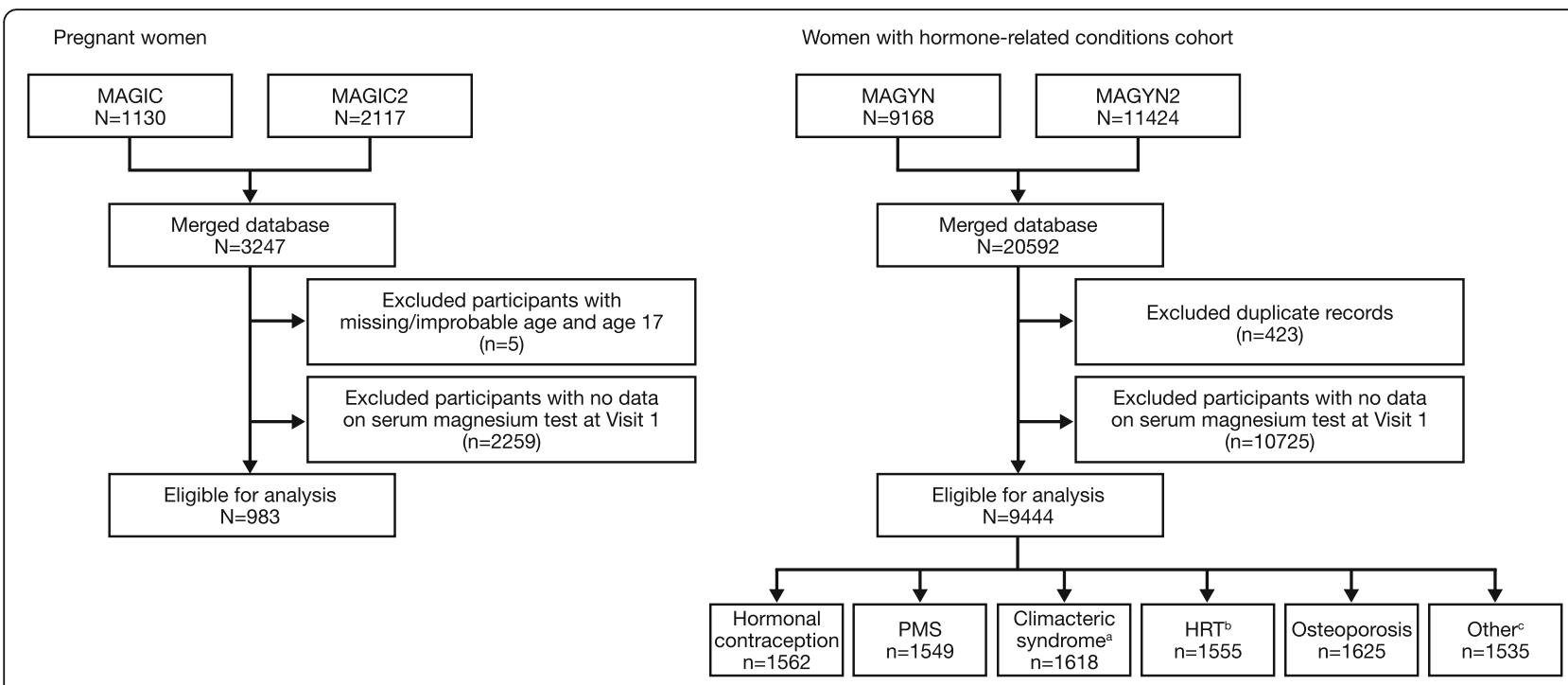

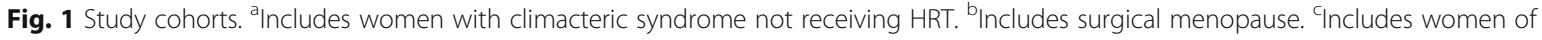
reproductive age with other hormonal conditions: endometriosis, polycystic ovarian disease, uterine leiomyoma, dysmenorrhea, endometrial hyperplasia. HRT, hormone replacement therapy; PMS, premenstrual syndrome

with hormone-related conditions'). Medical history that was available for the two cohorts of participants included any recorded terms that were relevant for this group: for example, for the 'pregnant women' cohort, the terms included complications and complaints associated with a previous pregnancy, whereas for the cohort of 'women with hormone-related conditions' the terms included general diseases and comorbidities. The rate of magnesium deficiency was estimated using two cut-offs: $0.66 \mathrm{mmol} / \mathrm{L}$, the traditional lower reference limit used in the Russian Federation and other countries [7], and $0.8 \mathrm{mmol} / \mathrm{L}$, the lower reference limit that has been recommended based on the recent studies $[3,8]$.

\section{Study objectives}

The objectives of the secondary analysis presented here were to characterize magnesium status, estimate the prevalence of hypomagnesemia and identify possible hypomagnesemia risk factors and associated comorbidities in pregnant women and in women with hormonerelated conditions.

\section{Statistical analysis}

Study cohorts were characterized using descriptive statistics. The cohort of pregnant women was treated as a single entity, whereas the cohort of women with hormone-related conditions was separated into subgroups according to their specific conditions. The prevalence of hypomagnesemia was assessed in both cohorts and in the subgroups of women with hormone-related conditions. All subgroups of women with hormone- related conditions were crosschecked for conflicting data on concomitant diseases, laboratory and clinical assessments; patients with missing, conflicting or improbable data were excluded from analysis.

Differences in magnesium levels between cohorts and subgroups were analyzed using the chi square test, unpaired $\mathrm{t}$-test and non-parametric tests. Univariate logistic regression analysis was performed to identify the risk factors and comorbid conditions associated with an increased risk of low serum magnesium level within both cohorts. The results were expressed as odds ratios with 95\% confidence intervals. Statistical significance threshold was set at $p<0.05$; the Bonferroni correction was applied to correct for the numerous multiple testing, leading to thresholds of $p<0.0005$ for pregnant women (up to 100 tests) and $p<0.0001$ for women with hormone-related conditions (up to 500 tests).

\section{Results}

\section{Study cohorts}

In total, 983 participants in the 'pregnant women' cohort and 9444 participants in the 'women with hormonerelated conditions' cohort were eligible for analysis. Women with hormone-related conditions included the following subgroups: women receiving hormonal contraception ( $n=1562$; among them, only 74 women were taking progestin-only formulations), women with premenstrual syndrome $(n=1549)$, women with climacteric syndrome not receiving HRT $(n=1618)$, women receiving HRT, including surgical menopause $(n=1555)$, women with osteoporosis $(n=1625)$ and women with 
other hormone-related conditions, such as endometriosis, polycystic ovarian disease, uterine leiomyoma, dysmenorrhea, endometrial hyperplasia $(n=1535)$ (Fig. 1).

Participants in the 'pregnant women' cohort had median age 28.0 (min-max 18-52), median body mass index (BMI) $23.1 \mathrm{~kg} / \mathrm{m}^{2}\left(\min -\max 15.9-50.3 \mathrm{~kg} / \mathrm{m}^{2}\right)$ and mean (standard deviation [SD]) serum magnesium level 0.714 (0.125) $\mathrm{mmol} / \mathrm{L}$ (Table 1).

Participants in the "women with hormone-related conditions' cohort had median age 44.0 years (min-max $18-$ 60 years), median BMI $25.0 \mathrm{~kg} / \mathrm{m}^{2}$ (min-max $13.8-63.4$ $\mathrm{kg} / \mathrm{m}^{2}$ ) and mean (SD) serum magnesium level 0.776 (0.198) $\mathrm{mmol} / \mathrm{L}$ (Table 1). Among different subgroups, women with osteoporosis, women with climacteric syndrome and women receiving HRT were on average older and had higher BMI than women in the other subgroups.

\section{Magnesium levels and prevalence of magnesium deficiency}

Participants in the 'pregnant women' cohort had lower mean serum magnesium levels than 'women with hormone-related conditions' $(0.714 \mathrm{mmol} / \mathrm{L}[\mathrm{SD}=0.125$ $\mathrm{mmol} / \mathrm{L}]$ vs $0.776 \mathrm{mmol} / \mathrm{L}[\mathrm{SD}=0.198 \mathrm{mmol} / \mathrm{L}], p<$ $0.0001)$. In the 'women with hormone-related conditions' cohort, the highest mean total serum magnesium level was found in the subgroup of women receiving hormonal contraception $(0.789 \mathrm{mmol} / \mathrm{L}[\mathrm{SD}=0.197 \mathrm{mmol} / \mathrm{L}])$, and the lowest - in women with osteoporosis $(0.758$ $\mathrm{mmol} / \mathrm{L}[\mathrm{SD}=0.199 \mathrm{mmol} / \mathrm{L}]$ ) (Table 1). The differences across subgroups were statistically significant $(p<$ 0.0001).

Prevalence of magnesium deficiency assessed by serum levels in 'pregnant women' cohort was $34.0 \%$ or $78.9 \%$ when using $0.66 \mathrm{mmol} / \mathrm{L}$ or $0.8 \mathrm{mmol} / \mathrm{L}$ as the cut-off, respectively (Fig. 2). Prevalence of magnesium deficiency assessed by serum blood levels in 'women with hormone-related conditions' cohort was $24.1 \%$ or $54.8 \%$ when using $0.66 \mathrm{mmol} / \mathrm{L}$ or $0.8 \mathrm{mmol} / \mathrm{L}$ as the cut-off, respectively (Fig. 2). Among all subgroups, the highest prevalence of magnesium deficiency was observed among women with osteoporosis $(28.0 \%$ using cut-off $<$ $0.66 \mathrm{mmol} / \mathrm{L}$ and $58.3 \%$ using cut-off $<0.8 \mathrm{mmol} / \mathrm{L}$ ) and women with climacteric syndrome (27.4 and 58.4\%, respectively).

\section{Potential risk factors associated with low serum magnesium levels in pregnant women}

In the 'pregnant women' cohort, several risk factors and comorbidities showed a statistically significant

Table 1 Baseline characteristics and magnesium status of study participants

\begin{tabular}{|c|c|c|c|c|c|c|c|c|}
\hline & \multirow{2}{*}{$\begin{array}{l}\text { Pregnant } \\
\text { women } \\
(N=983)\end{array}$} & \multicolumn{7}{|c|}{ Women with hormone-related conditions } \\
\hline & & $\begin{array}{l}\text { Hormonal } \\
\text { contraception } \\
(n=1562)\end{array}$ & $\begin{array}{l}\text { Premenstrual } \\
\text { syndrome } \\
(n=1549)\end{array}$ & $\begin{array}{l}\text { Climacteric } \\
\text { syndrome }^{a, b} \\
(n=1618)\end{array}$ & $\begin{array}{l}\mathrm{HRT}^{\mathrm{b}} \\
(n=1555)\end{array}$ & $\begin{array}{l}\text { Osteoporosis } \\
(n=1625)\end{array}$ & $\begin{array}{l}\text { Other }^{c} \\
(n=1535)\end{array}$ & $\begin{array}{l}\text { Total } \\
(N=9444)\end{array}$ \\
\hline \multicolumn{9}{|l|}{ Age, years } \\
\hline $\mathrm{n} / \mathrm{missing}$ & $983 / 0$ & $1562 / 0$ & $1549 / 0$ & $1618 / 0$ & $1555 / 0$ & $1625 / 0$ & $1535 / 0$ & $9444 / 0$ \\
\hline Median & 28.0 & 30.0 & 29.0 & 51. & 50.0 & 55.0 & 36.0 & 44.0 \\
\hline Q1; Q3 & $25.0 ; 32.0$ & $25.0 ; 34.0$ & $25.0 ; 35.0$ & $48.0 ; 54.0$ & $47.0 ; 54.0$ & $51.0 ; 58.0$ & $30.0 ; 42.0$ & $31.0 ; 52.0$ \\
\hline Min; Max & $18 ; 52$ & $18 ; 55$ & $18 ; 56$ & $29 ; 60$ & $23 ; 60$ & $19 ; 60$ & $18 ; 59$ & $18 ; 60$ \\
\hline \multicolumn{9}{|l|}{$\mathrm{BMI}, \mathrm{kg} / \mathrm{m}^{2}$} \\
\hline $\mathrm{n} / \mathrm{missing}$ & $983 / 0$ & $1554 / 8$ & $1540 / 9$ & 1609/9 & $1546 / 9$ & $1620 / 5$ & $1532 / 3$ & $9401 / 43$ \\
\hline Median & 23.10 & 22.10 & 22.40 & 27.20 & 26.30 & 27.10 & 24.20 & 25.00 \\
\hline Q1; Q3 & $20.90 ; 26.40$ & $20.30 ; 24.60$ & $20.30 ; 25.20$ & $24.70 ; 30.50$ & $24.00 ; 29.00$ & $24.30 ; 30.50$ & $21.80 ; 27.40$ & $22.00 ; 28.30$ \\
\hline Min; Max & $15.9 ; 50.3$ & $14.6 ; 48.5$ & $15.6 ; 43.7$ & $15.2 ; 63.4$ & $13.8 ; 60.6$ & $15.2 ; 51.8$ & $14.8 ; 52.1$ & $13.8 ; 63.4$ \\
\hline \multicolumn{9}{|c|}{ Total blood serum magnesium, $\mathrm{mmol} / \mathrm{L}$} \\
\hline $\mathrm{n} /$ missing & $983 / 0$ & $1562 / 0$ & $1549 / 0$ & $1618 / 0$ & $1555 / 0$ & $1625 / 0$ & $1535 / 0$ & $9444 / 0$ \\
\hline Mean (SD) & $0.714(0.125)$ & $0.789(0.197)$ & $0.787(0.193)$ & $0.765(0.198)$ & $0.787(0.219)$ & $0.758(0.199)$ & $0.771(0.180)$ & $0.776(0.198)$ \\
\hline Median & 0.700 & 0.780 & 0.790 & 0.750 & 0.780 & 0.750 & 0.770 & 0.770 \\
\hline Q1; Q3 & $0.650 ; 0.780$ & $0.680 ; 0.900$ & $0.680 ; 0.890$ & $0.650 ; 0.860$ & $0.680 ; 0.890$ & $0.640 ; 0.860$ & $0.660 ; 0.890$ & $0.660 ; 0.890$ \\
\hline Min; Max & $0.12 ; 1.92$ & $0.09 ; 2.41$ & $0.14 ; 2.50$ & $0.20 ; 2.50$ & $0.10 ; 4.08$ & $0.20 ; 2.20$ & $0.08 ; 2.50$ & $0.08 ; 4.08$ \\
\hline
\end{tabular}

$B M I$ Body mass index, HRT Hormone replacement therapy, $Q$ Quartile

${ }^{a}$ Women with climacteric syndrome not receiving HRT

${ }^{b}$ Including surgical menopause

${ }^{c}$ Women of reproductive age with other hormonal conditions: endometriosis, polycystic ovarian disease, uterine leiomyoma, dysmenorrhea,

endometrial hyperplasia 

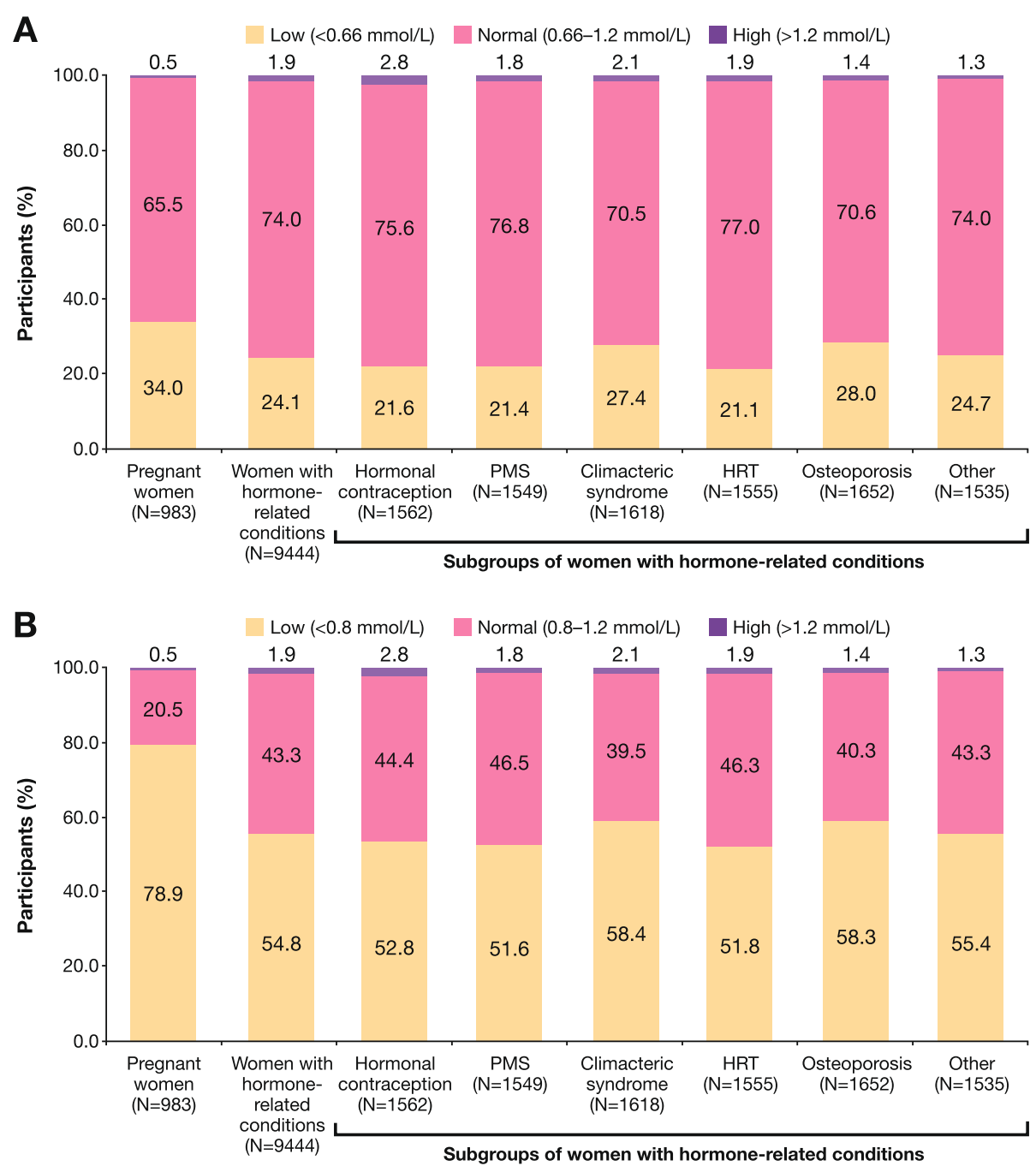

Fig. 2 Proportion of participants according to serum magnesium status at baseline using $0.66 \mathrm{mmol} / \mathrm{L}$ a or $0.8 \mathrm{mmol} / \mathrm{L} \mathbf{b}$ as the cut-off. HRT, hormone replacement therapy; PMS, premenstrual syndrome

association with low serum magnesium levels $(p \leq$ 0.0005; Supplementary Table 1). For the cut-off of < $0.66 \mathrm{mmol} / \mathrm{L}$, significant associations included increase in systolic blood pressure $(p=0.0003)$, increase in diastolic blood pressure $(p<0.0001)$, endocrine disorders $(p=0.0002)$, previous pregnancy complications (such as placental insufficiency $[p<0.0001])$, and complaints (edema $[p<0.0001]$ and pelvic girdle pain $[p=0.0004]$ ). Edema was the only risk factor significantly associated with hypomagnesemia defined by the cut-off of $<0.8$ $\mathrm{mmol} / \mathrm{L}(p<0.0001)$ (Fig. 3; Supplementary Table 1).

\section{Potential risk factors associated with low serum magnesium levels in women with hormone-related conditions}

In the 'women with hormone-related conditions' cohort, a large number of risk factors and comorbidities showed a statistically significant association with low serum magnesium (26 factors for cut-off $<0.66 \mathrm{mmol} / \mathrm{L}$ and 38 factors for cut-off $<0.8 \mathrm{mmol} / \mathrm{L}$; Supplementary Table 2). Factors associated with both cut-offs included age and BMI $(p<0.0001$ for all). All studied symptoms of magnesium deficiency were significantly associated with low serum magnesium $(p<0.0001$ for all). Furthermore, the potential risk factors included various comorbidities and previous obstetric and gynecological conditions outlined below.

The association was significant for the following comorbidities: gastrointestinal diseases (hepatitis $[p<$ 0.0001 for both cut-offs] and cholelithiasis $[p<0.0001$ for both cut-offs]), urolithiasis [ $p<0.0001$ for both cutoffs], cardiovascular diseases (pathology of heart valves $[p \leq 0.0001$ for both cut-offs]), and hypothyroidism ( $p<$ 0.0001 for both cut-offs) (Supplementary Table 2). 


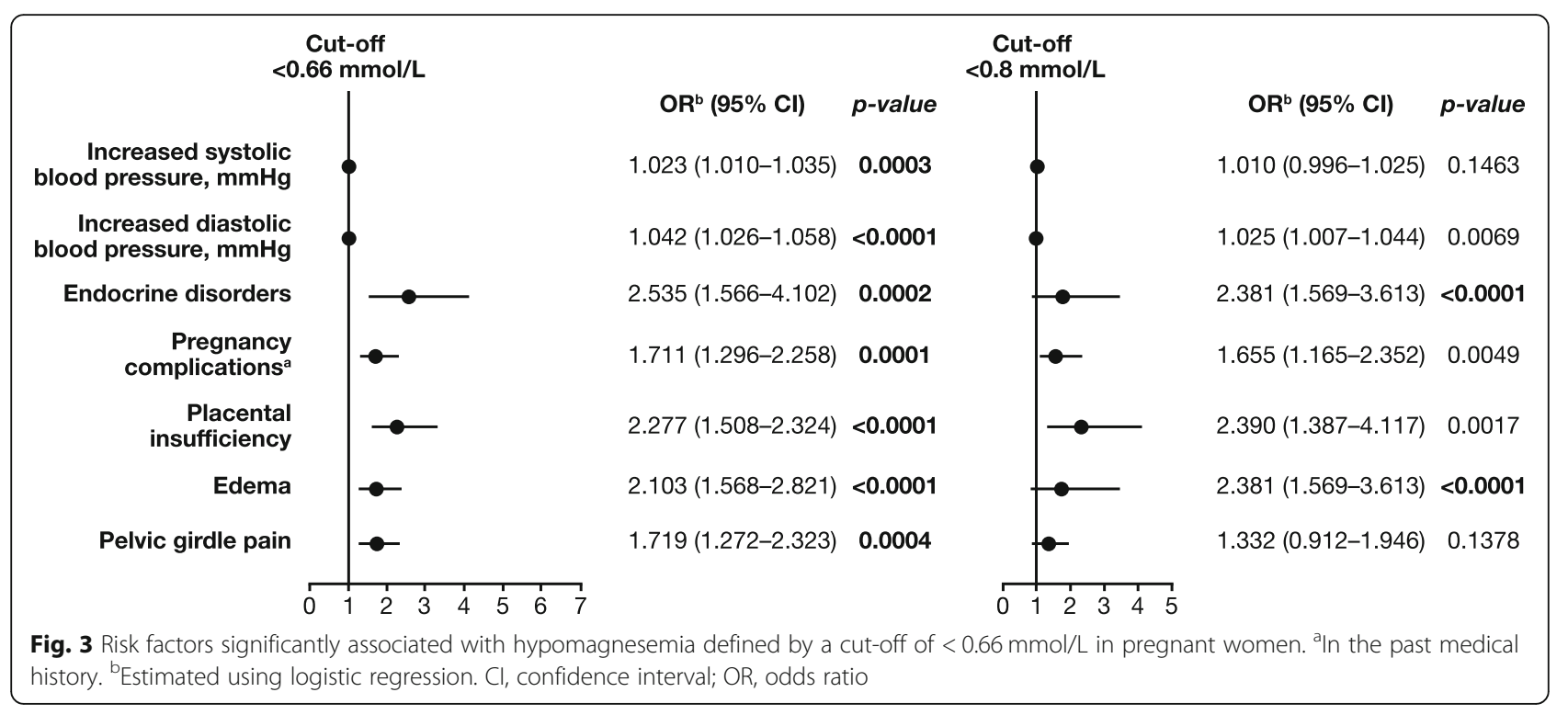

The association was also significant for previous obstetric and gynecological conditions, such as endometriosis ( $p=0.0001$ for both cut-offs) and complications of pregnancy and childbirth (including preeclampsia $[p<$ 0.0001 for both cut-offs] and feto-placental insufficiency [ $p<0.0001$ for both cut-offs]), (Fig. 4).

Among factors that defined the subgroups of 'women with hormone-related conditions', osteoporosis was significantly associated with hypomagnesemia using the cut-off of $0.66 \mathrm{mmol} / \mathrm{L}(p<0.0001)$. Associations for all risk factors and both cut-offs are listed in the Supplementary Table 2 .

\section{Magnesium supplementation}

Participants of observational studies MAGIC, MAGIC2, MAGYN and MAGYN2 received magnesium supplements prescribed by treating physicians in accordance to routine clinical practice; a proportion of participants received magnesium-vitamin $\mathrm{B} 6$ combination (Magne $\mathrm{B}_{6}$ / Magne $\mathrm{B}_{6}$ Forte) [18-21]. The effectiveness results are

\begin{tabular}{|c|c|c|c|c|c|c|}
\hline \multicolumn{2}{|c|}{ Cut-off $<0.66 \mathrm{mmol} / \mathrm{L}$} & $\mathrm{OR}^{\mathrm{a}}(95 \% \mathrm{Cl})$ & p-value & Cut-off $<0.8 \mathrm{mmol} / \mathrm{L}$ & $\mathrm{OR}^{\mathrm{a}}(95 \% \mathrm{Cl})$ & p-value \\
\hline $\begin{array}{l}\text { Hyper-poly-menorrhea, } \\
\text { abnormal uterine bleeding }\end{array}$ & - & $1.240(1.034-1.487)$ & 0.0200 & e & $1.404(1.186-1.660)$ & 0.0001 \\
\hline Climacteric syndrome & 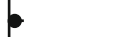 & $1.149(1.013-1.304)$ & 0.0313 & b & $1.268(1.132-1.419)$ & $<0.0001$ \\
\hline Urinary incontinence & $\rightarrow$ & $1.671(1.311-2.129)$ & $<0.0001$ & $\bullet$ & $1.453(1.145-1.844)$ & 0.0021 \\
\hline Endometriosis & $\bullet$ & $1.284(1.130-1.459)$ & 0.0001 & 3 & $1.261(1.122-1.416)$ & 0.0001 \\
\hline Infertility & - & $1.368(1.090-1.716)$ & 0.0068 & - & $1.606(1.290-1.999)$ & $<0.0001$ \\
\hline $\begin{array}{r}\text { Complications of pregnancy } \\
\text { and childbirth }\end{array}$ & $\bullet$ & $1.325(1.172-1.498)$ & $<0.0001$ & - & $1.457(1.301-1.631)$ & $<0.0001$ \\
\hline Syndrome of miscarriage & $\rightarrow-$ & $1.893(1.414-2.535)$ & $<0.0001$ & $\bullet$ & $1.677(1.243-2.263)$ & 0.0007 \\
\hline Threatened miscarriage & - & $1.205(1.040-1.397)$ & 0.0131 & $\bullet$ & $1.453(1.269-1.664)$ & $<0.0001$ \\
\hline Preeclampsia & $\rightarrow$ & $2.325(1.739-3.108)$ & $<0.0001$ & $\rightarrow-$ & $3.047(2.152-4.314)$ & $<0.0001$ \\
\hline Feto-placental insufficiency & $\rightarrow$ & $1.872(1.508-2.324)$ & $<0.0001$ & $\bullet$ & $1.955(1.560-2.450)$ & $<0.0001$ \\
\hline $\begin{array}{r}\text { Gynecological and } \\
\text { obstetric operations }\end{array}$ & $\bullet$ & $1.266(1.099-1.458)$ & 0.0011 & & $1.317(1.157-1.499)$ & $<0.0001$ \\
\hline $\begin{array}{r}\text { Diffuse form of } \\
\text { fibrocystic mastopathy }\end{array}$ & - & $1.253(1.102-1.426)$ & 0.0006 & 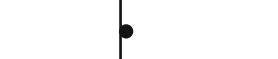 & $1.258(1.119-1.414)$ & 0.0001 \\
\hline & $\begin{array}{lll}4 & 1 & 3\end{array}$ & 6 & & $\begin{array}{lllllll} & 1 & 1 & 1 & 1 & 1\end{array}$ & & \\
\hline
\end{tabular}

Fig. 4 Risk factors from the category 'obstetric and gynecological past medical history and status' associated with hypomagnesemia defined by a cut-off of $<0.66 \mathrm{mmol} / \mathrm{L}$ in women with hormone-related conditions. Cl, confidence interval; OR, odds ratio. ${ }^{a}$ Estimated using logistic regression 
presented in detail elsewhere [22]. Briefly, after taking magnesium supplements for 4 weeks, 293 of 318 (92.1\%) pregnant women with initial level $<0.66 \mathrm{mmol} / \mathrm{L}$ achieved magnesium level $\geq 0.66 \mathrm{mmol} / \mathrm{L}$, and 529 of 717 (73.8\%) pregnant women with initial level $<0.8$ $\mathrm{mmol} / \mathrm{L}$ achieved magnesium level $\geq 0.8 \mathrm{mmol} / \mathrm{L}$. The corresponding proportions among women with hormone-related conditions were $78.4 \%$ (283 or 361 women) and $58.9 \%$ (452 of 767 women), respectively.

\section{Discussion}

This study was one of the largest and the most comprehensive real-world studies of magnesium deficiency in women. The study cohorts consisted of pregnant women and women with hormone-related conditions from multiple cities and regions of the Russian Federation, providing wide geographical coverage and a large sample size (a total of 10,427 women).

The prevalence of magnesium deficiency in the studied population was extremely high, reaching $78.9 \%$ in pregnant women and $54.8 \%$ in women with hormone-related conditions. These rates are among the highest cited in literature; however, one should keep in mind that participants of MAGIC and MAGIC2 studies were enrolled based on clinical suspicion of magnesium deficiency. Furthermore, the analysis of MAGYN and MAGYN2 study included only women with serum magnesium level assessment at Visit 1, i.e. those with suspected magnesium deficiency. Nevertheless, these results complement other studies, including those assessing magnesium levels in general adult populations of Germany, Mexico, Taiwan and the USA that found higher prevalence of hypomagnesemia in women $(21.0-40.0 \%)$ than in men (1.5-35.4\%) [2, 23-25]. In these studies, magnesium deficiency was determined using cut-offs between 0.76 $\mathrm{mmol} / \mathrm{L}$ and $0.85 \mathrm{mmol} / \mathrm{L}$ [2, 23-25]. High rates of hypomagnesemia have been reported in pregnant women in India (43.6\%) and Sudan (57.2\%); both studies used a cut-off of $0.74 \mathrm{mmol} / \mathrm{L}[26,27]$. The results of the present study confirm the general observations that pregnant women, women receiving oral contraceptives, postmenopausal women and women with osteoporosis are at a particular risk of hypomagnesemia [9, 16, 17]. The multifactorial reasons for the increased risk during pregnancy have been discussed in detail elsewhere and include fetal demand, altered tissue distribution and an increased renal output of magnesium [9]. High estrogen levels may also influence magnesium utilization in tissues and may account for subnormal serum magnesium levels in young women receiving oral contraceptives, with multiple gender-specific physiological ageing processes accounting for low magnesium in women with osteoporosis $[4,17]$. Irrespective of the underlying cause, there is an argument for the use of magnesium supplementation in women who are at risk of hypomagnesemia, including pregnant women and women with hormone-related conditions. Notably, among various subgroups of women with hormone-related conditions, women with osteoporosis had the highest incidence of hypomagnesemia $(28.0 \% / 58.3 \%$ using cut-off $<0.66 / 0.8$ $\mathrm{mmol} / \mathrm{L}$ ), but also had the highest rate of achieving target serum magnesium level with magnesium supplementation $(88.1 \% / 58.8 \%$ using cut-off $<0.66 / 0.8 \mathrm{mmol} /$ L). These results emphasize a possible role for magnesium supplementation in the prevention or treatment of various gynecological conditions that could be explored in future studies.

Several risk factors associated with low magnesium levels have been identified in the studied cohorts. The broad variety of conditions and comorbidities found in this study are in line with the previous studies in pregnant women and the general population (e.g. cardiovascular comorbidities) and further expand the current knowledge of the effect of hypomagnesemia on women's health. In pregnant women, risk factors for both 0.66 $\mathrm{mmol} / \mathrm{L}$ and $0.8 \mathrm{mmol} / \mathrm{L}$ cut-offs included increased diastolic blood pressure, previous pregnancy complications, such as preeclampsia and placental insufficiency, and edema. Previous studies have identified placental insufficiency, preeclampsia, miscarriage, premature birth and gestational diabetes as conditions and outcomes associated with low magnesium levels [9]. Magnesium sulphate is recommended by the WHO for the prevention and treatment of eclampsia [28]. However, despite its wide use in clinical practice, the dosing regimens vary across countries and are often inconsistent with the international recommendations [29]. Our results further strengthen the clinical evidence supporting a direct link between magnesium supplementation and risk of preeclampsia and may help facilitate the uptake of the WHO guidelines throughout the world. It may also be interesting to test in further clinical studies whether the use of over-the-counter magnesium supplements in pregnant women decreases the risk of preeclampsia and the need for intravenous magnesium administration.

In women with hormone-related conditions, risk factors for both $0.66 \mathrm{mmol} / \mathrm{L}$ and $0.8 \mathrm{mmol} / \mathrm{L}$ cut-offs included age and BMI, all studied symptoms of magnesium deficiency, and a number of previous gynecological conditions and general comorbidities. Our analysis found significant associations between the risk of low magnesium and various general comorbidities, including general stress (various laboratory and hormone values) in women with hormone-related conditions. These observations support previous reports linking immune dysfunction and general stress to magnesium deficiency [30, 31]. The large number of risk factors associated with hypomagnesemia in this study confirms the status of 
magnesium as one of the essential elements in health and supports further clinical research investigating the role of magnesium in various neurological, gastrointestinal and cardiovascular conditions.

This study has several limitations. The observational studies MAGIC and MAGIC2 collected data on pregnant women with suspected magnesium deficiency, and it is not possible to generalize these results to the overall population. However, the study generated an important insight into hypomagnesemia in a larger cohort of women with hormone-related conditions (MAGYN and MAGYN2). Because of the retrospective observational design of this study, no causal links can be established between magnesium deficiency and associated conditions. Due to the retrospective nature of the analysis, only data that were recorded previously were included, and it was not possible to acquire new information on patient medical history. For instance, viral infections and edema were included in medical history in general terms, and no details were reported with regard to specific viruses or the edema site. These results should therefore be interpreted with caution.

Because the study included participants with suspected magnesium deficiency, the risk of selection bias was high, and the actual prevalence of hypomagnesemia in Russia may be lower than revealed in this study. However, similarly high prevalence of hypomagnesemia has been reported previously [26, 27]. Additionally, pregnancy and hormone-related conditions could be considered as risk factors for magnesium deficiency in general. One may argue that the use of a high cut-off of $<0.8$ $\mathrm{mmol} / \mathrm{L}$ resulted in an artificially increased prevalence detected in this study. The appropriate cut-off has been a matter of debate in literature $[3,8]$, and future studies will undoubtedly contribute to a consensus on the most clinically relevant cut-off value. Another limitation of this work is that the analysis did not take into account environmental risk factors and social aspects which may have contributed to magnesium deficiency in the study population. Finally, univariate analysis was selected as the simplest method that could provide an exploratory descriptive assessment of potential risk factors for hypomagnesemia. The choice of univariate analysis may be considered a limitation; further studies should include a confirmatory multivariate analysis of potential risk factors.

\section{Conclusions}

This is one of the largest and most representative analyses of magnesium deficiency in pregnant women and women with hormone-related conditions. The study provided an estimate of the prevalence of hypomagnesemia in these cohorts and identified multiple risk factors and associated comorbidities, providing unique insights into the epidemiology of magnesium deficiency in the Russian Federation. These results call for further studies of the prevalence and epidemiology of hypomagnesemia among the general population.

\section{Supplementary Information}

The online version contains supplementary material available at https://doi. org/10.1186/s12884-021-03558-2.

\section{Additional file 1}

\section{Abbreviations}

BMI: Body mass index; Cl: Confidence interval; MDQ: Magnesium deficiency questionnaire; HRC: Hormone-related conditions; HRT: Hormone replacement therapy; OR: Odds ratio; PMS: Premenstrual syndrome; Q: Quartile;

SD: Standard deviation; WHO: World Health Organization

\section{Acknowledgements}

The authors are grateful to the participants included in the studies, the investigators, coordinators and study teams. The authors thank Atlant Clinical Ltd. Clinical Research Organization for protocol co-development and conducting the analysis, and Dr. Lionel Noah and Beatrice Bois de Fer of Consumer Healthcare, Sanofi, Paris, France, for critical review of the manuscript. Editorial support was provided by Olga Ucar and Mark Davies of inScience Communications, Springer Healthcare Ltd., UK, and was funded by Sanofi.

\section{Authors' contributions}

SO: Development of study design, data collection, data analysis, manuscript review/editing. GD: Development of study design, data collection, data analysis, manuscript review/editing. GP: Development of study design, data collection, data analysis, manuscript review/editing. NY: Development of study design, data collection, data analysis, manuscript review/editing. KS: Development of protocol, development of study design, data collection, data analysis, critical review and editing of the manuscript. SK: Development of study design, data collection, data analysis, manuscript review/editing. $A B$ : Development of study design, data collection, data analysis, manuscript review/editing. All authors also have read and approved the final version of the manuscript.

\section{Funding}

MAGIC, MAGIC2, MAGYN, MAGYN2 and the present secondary analysis were sponsored by Sanofi - Sanofi research representative (Kirill Starostin) being a Sanofi employee has taken part in development of the study protocol, study design, data collection and analysis, critical review and editing of the manuscript

\section{Availability of data and materials}

Qualified researchers may request access to patient-level data and related documents. Data may be shared upon request by contacting corresponding author (Kirill Starostin). Patient-level data are anonymized, and study documents will be redacted to protect the privacy of trial participants. Further details on Sanofi's data sharing criteria, eligible studies, and process for requesting access can be found at https://www.clinicalstudydatarequest.com. Other part of this study (Orlova et al, 2020) dedicated to magnesium deficiency questionnaire analysis and shortening is published recently and the reader may be kindly referred to that manuscript as well (see reference \#22).

\section{Ethics approval and consent to participate}

The study consisted of a secondary analysis of existing already anonymised data and therefore did not require an ethics approval. All primary observational studies (MAGIC, MAGIC2, MAGYN, MAGYN2) were approved by independent ethical committee and were conducted in accordance with the principles of good clinical practice and the laws of the Russian Federation.

Consent for publication

Not applicable. 


\section{Competing interests}

Starostin K., Konchits S., and Bevz A are Sanofi employees. Other authors declare no potential conflict of interest.

\section{Author details}

'Department of Dietetics and Clinical Nutritiology of Continuing Medical Education, Medical Institute, RUDN University, Moscow, Russia. ${ }^{2}$ Department of Obstetrics and Gynecology with a course of Reproductive Medicine, The Academy of Medical Education. F.I. Inozemtsev, Saint-Petersburg, Russia. ${ }^{3}$ Department of Clinical Pharmacology Inserm CIC 1405, University Hospital, Clermont-Ferrand, France. ${ }^{4}$ Department of General Medicine, The Yaroslavl State Medical University Institute of Postgraduate Education, Yaroslavl, Russia. ${ }^{5}$ Department of Medical Affairs, Sanofi, Moscow, Russia.

Received: 21 July 2020 Accepted: 13 January 2021

Published online: 22 January 2021

\section{References}

1. Ismail AAA, Ismail NA. Magnesium: A mineral essential for health yet generally underestimated or even ignored. J Nutr Food Sci. 2016;6:523. https://doi.org/10.4172/2155-9600.1000523.

2. Costello RB, Elin RJ, Rosanoff A, Wallace TC, Guerrero-Romero F, Hruby A Lutsey PL, Nielsen FH, Rodriguez-Moran M, Song Y, et al. Perspective: the case for an evidence-based reference interval for serum magnesium: the time has come. Adv Nutr. 2016;7(6):977-93.

3. DiNicolantonio JJ, O'Keefe JH, Wilson W. Subclinical magnesium deficiency: a principal driver of cardiovascular disease and a public health crisis. Open Heart. 2018;5(1):e000668.

4. Workinger JL, Doyle RP, Bortz J. Challenges in the diagnosis of magnesium status. Nutrients. 2018;10(9).

5. Gröber U, Schmidt J, Kisters K. Magnesium in prevention and therapy Nutrients. 2015;7(9):8199-226.

6. Abbott LG, Rude RK. Clinical manifestations of magnesium deficiency. Miner Electrolyte Metab. 1993;19(4-5):314-22.

7. Bell C. Clinical guide to laboratory tests. 3rd edition. Norbert W. Tietz, ed. Transfusion. 2009;35(11):972.

8. Elin RJ. Assessment of magnesium status for diagnosis and therapy. Magnes Res. 2010;23(4):S194-8.

9. Spätling L, Classen HG, Kisters K, Liebscher U, Rylander R, et al. Supplementation of magnesium in pregnancy. J Preg Child Health. 2017;4: 302. https://doi.org/10.4172/2376-127X.1000302.

10. Wiles K, Chappell L, Clark K, Elman L, Hall M, Lightstone L, Mohamed G, Mukherjee D, Nelson-Piercy C, Webster P, et al. Clinical practice guideline on pregnancy and renal disease. BMC Nephrol. 2019;20(1):401.

11. Farzin L, Sajadi F. Comparison of serum trace element levels in patients with or without pre-eclampsia. J Res Med Sci. 2012;17(10):938-41.

12. Jain S, Sharma P, Kulshreshtha S, Mohan G, Singh S. The role of calcium, magnesium, and zinc in pre-eclampsia. Biol Trace Elem Res. 2010;133(2): 162-70.

13. Makrides M, Crosby DD, Bain E, Crowther CA. Magnesium supplementation in pregnancy. Cochrane Database Syst Rev. 2014;4:CD000937.

14. Sukonpan K, Phupong V. Serum calcium and serum magnesium in normal and preeclamptic pregnancy. Arch Gynecol Obstet. 2005;273(1):12-6.

15. Zarean $E$, Tarjan A. Effect of magnesium supplement on pregnancy outcomes: a randomized control trial. Adv Biomed Res. 2017:6:109.

16. Palmery M, Saraceno A, Vaiarelli A, Carlomagno G. Oral contraceptives and changes in nutritional requirements. Eur Rev Med Pharmacol Sci. 2013; 17(13):1804-13.

17. Welch AA, Skinner J, Hickson M. Dietary magnesium may be protective for aging of bone and skeletal muscle in middle and younger older age men and women: cross-sectional findings from the UK Biobank Cohort. Nutrients. 2017;9(11):1189. https://doi.org/10.3390/nu9111189.

18. Makatsariya AD, Dadak C, Bitsadze VO, Solopova AG, Khamani NM. Clinical features of patients with hormone-dependent conditions and magnesium deficiency. Akusherstvo i ginekologiia. 2017:5(2017):124-31.

19. Makatsariya AD, Bitsadze VO, Khizroeva DK, Dzhobava EM. Prevalence of magnesium deficiency in pregnant women. Voprosy Ginekologii Akusherstva Perinatologii. 2012;11(5):25-34.
20. Serov VN, Baranov II, Blinov DV, Zimovina UV, Sandakova EA, Ushakova TI. Results of evaluating mg deficiency among female patients with hormonerelated conditions. Akusherstvo Ginekologiia. 2015;6:91-7.

21. Serov VN, Blinov DV, Zimovina UV, Dzhobava EM. Results of an investigation of the prevalence of magnesium deficiency in pregnant women. Akusherstvo Ginekologiia. 2014;6:33-40.

22. Orlova S, Dikke G, Pickering G, Konchits S, Starostin K, Bevz A. Magnesium Deficiency Questionnaire: A New Non-Invasive Magnesium Deficiency Screening Tool Developed Using Real-World Data from Four Observational Studies. Nutrients. 2020;12(7).

23. Schimatschek HF, Rempis R. Prevalence of hypomagnesemia in an unselected German population of 16,000 individuals. Magnes Res. 2001; 14(4):283-90.

24. Wang JL, Weng YL, Pan WH, Kao MD. Trends and nutritional status for magnesium in Taiwan from NAHSIT 1993 to 2008. Asia Pac J Clin Nutr. 2011; 20(2):266-74

25. Lowenstein FW, Stanton MF. Serum magnesium levels in the United States, 1971-1974. J Am Coll Nutr. 1986;5(4):399-414.

26. Pathak P, Kapoor SK, Kapil U, Dwivedi SN. Serum magnesium level among pregnant women in a rural community of Haryana state, India. Eur J Clin Nutr. 2003:57(11):1504-6.

27. Eltayeb R, Rayis DA, Sharif ME, Ahmed ABA, Elhardello O, Adam I. The prevalence of serum magnesium and iron deficiency anaemia among Sudanese women in early pregnancy: a cross-sectional study. Trans R Soc Trop Med Hyg. 2019;113(1):31-5.

28. WHO recommendations for prevention and treatment of pre-eclampsia and eclampsia. @ World Health Organization 2011, 38 pages, ISBN 97892 41548335.

29. Long Q, Oladapo OT, Leathersich S, Vogel JP, Carroli G, Lumbiganon P, Qureshi Z, Gulmezoglu AM. Maternal WHOMSo, Newborn Health Research $\mathrm{N}$ : clinical practice patterns on the use of magnesium sulphate for treatment of pre-eclampsia and eclampsia: a multi-country survey. BJOG 2017;124(12):1883-90

30. Slagle P. Magnificent magnesium. In: The Way Up Newsletter, vol. 30; 2001.

31. Tam M, Gomez S, Gonzalez-Gross M, Marcos A. Possible roles of magnesium on the immune system. Eur J Clin Nutr. 2003;57(10):1193-7.

\section{Publisher's Note}

Springer Nature remains neutral with regard to jurisdictional claims in published maps and institutional affiliations.
Ready to submit your research? Choose BMC and benefit from:

- fast, convenient online submission

- thorough peer review by experienced researchers in your field

- rapid publication on acceptance

- support for research data, including large and complex data types

- gold Open Access which fosters wider collaboration and increased citations

- maximum visibility for your research: over $100 \mathrm{M}$ website views per year

At BMC, research is always in progress.

Learn more biomedcentral.com/submissions 